\title{
Experiencing the Essence of Learning Database Management System Course using C-map Tool
}

\author{
R. Hima Sagarika ${ }^{1,}$ Syedkhamruddin ${ }^{2}$ \\ ${ }^{1}$ Department of Computer Science and Engineering, KG Reddy College of Engineering \& Technology, Hyderabad \\ ${ }^{2}$ Department of Electrical and Electronics Engineering, KG Reddy College of Engineering \& Technology, Hyderabad \\ ${ }^{1}$ sagarika.rayapudi@gmail.com \\ ${ }^{2}$ syedkhamruddin@kgr.ac.in
}

\begin{abstract}
One of the never ending concerns in engineering education is the ability of the students to apply the content they learned to the real world situations. But the major problem occurs in understanding the organizational structure of entire course and its application. To address this the paper presents the implementation of concept maps to Database Management System (DBMS) course using Cmap tool. A case study has been conducted to compare the results with conventional instruction and concept map based instruction. This study fosters the effective learning through technology tools integrated with content and pedagogy.
\end{abstract}

Keywords: Concept map, Enduring Outcome, Curricular Priorities, Database Management system.

\section{Introduction}

Computer science and Engineering curriculums have database management system course. In this traditional course students must study various principles that relate to database management and/or database design. The principles include the conceptual and logical database design, based on widely accepted Entity-Relationship model, with normalization used as a validation technique. The course also covers the mapping of the logical design to a physical implementation. When the course is taught for service disciplines it is very challenging task to teach a database theory course for students with limited math skills and no prerequisites knowledge on computer related content. As an open elective the database management system course is introduced for disciplines other than computer sciences. As a growing field the DBMS course plays a major role in the real world where multidisciplinary teams are working on the real complex problems. But students are lacking in the structural knowledge where it is being hard to identify the connection between the concepts and applying to the real world problems. Structural knowledge may be seen as a separate type of knowledge

\author{
R. Hima Sagarika \\ Department of CSE, KGRCET, Hyderabad \\ sagarika.rayapudi@gmail.com
}

(Jonassen \& Grabowski, 1993). It describes how prior knowledge is interconnected (Brinley et al., 2019). Most previous research has not used assessments thought to measure meaning-ful learning, which refers to students' abilities to make inferences and exhibit deep understanding of concepts (Anderson et al., 2000). This knowledge can be better gained through the concept mapping techniques which is present in this paper. The structural knowledge of the database management course is explained by using cmap tool to draw the concept maps in this study.

Database management System is software which can be stored and retrieve the data in a convenient and efficient way. The prior knowledge required for the database management system is Mathematical foundations, basics of computer and computer programming. The course includes basic operations performed on the database are create, insert, alter, update, modify, delete. Main concepts of the course are

- Database structure and applications

- Relational algebra

- Schema refinement

- Transaction techniques

- $\quad$ Storage Structure and indexing

Concept Map was introduced by Novak (Novak \& Gowin, 1984) as a graphical tool for representing knowledge structure in the form of a graph. They also enhance a meaningful learning around a focus topic. A concept map simply uses a series of information that connects around a topic. The concept map helps students to organize their thinking. This concept map can design using a tool C-map, mind mup, etc. In this paper the author represented the mapping in three phases by implementing curricular priorities. 
- Enduring Outcome

- Important to know

- Worth being Familiar with

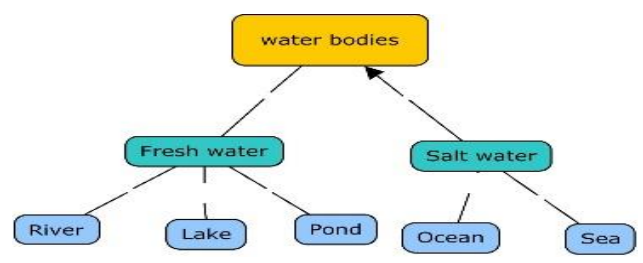

Fig 1. A Sample representation for concept map

A sample concept map representation is shown in the Fig. 1. There are many different ways Concept Maps can be designed and executed to represent knowledge and/or to assess learning, as summarized in (Strautmane, 2012). The concept maps could be representation to map the concept and pedagogy, concept and technology, pedagogy and technology and so on. This paper presents the concept maps in which the content of the course are identified with different curricular priorities and mapped.

\section{Methodology}

Database Management System course is selected to compare the effective learning using the concept maps. The course is chosen as an open elective for Electrical and Electronics (EEE) and also for Electronics and Communication (ECE) students. Traditional teaching is carried out for the same course in the academic year (AY) 2017-18. Concept map is used to enhance the learning of DBMS in 2018-19 AY. The logic of backward design process is used for the curriculum. The implementation of the methodology is carried out in the below phases:

1. Backward design process

2. Curricular priorities and Assessment methods

3. Concept maps using C-map tool

\section{A. Backward design process}

Backward design process includes identifying the desired results (Course Outcomes), determining the acceptable evidences (Planning Assessments) and planning the instructions (Pedagogical activities) as shown in the Fig.2.

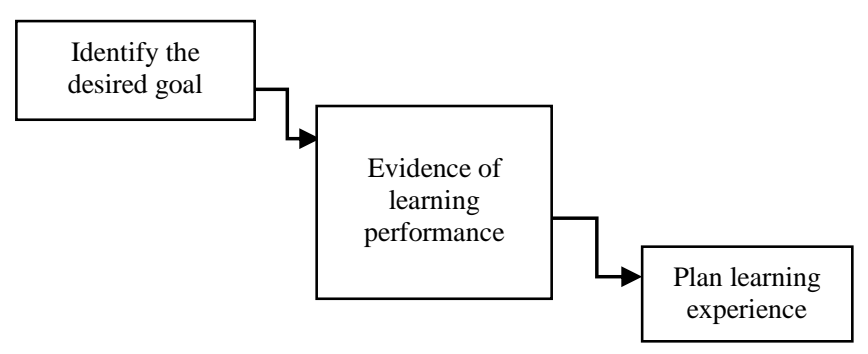

Fig. 2 Background design process
The steps required for the above design are:

Step 1: It includes what the students should be able to do at the end of the course.

Step 2: Examine the students that they have achieved the desired result or not.

Step 3: Plan the pedagogical activities suitable for the course content and implement.

\section{B. Curricular priorities and Assessment methods}

Curricular priorities for the course have been identified as "Enduring Outcomes", "Important to know" and "Worth being familiar with" shown in Fig. 3. Enduring Outcomes are the learning outcomes of the topics which should endure (long) after the class is over. "Enduring Outcomes" may be difficult concepts, misconception concepts or threshold concepts that need to be mastered before subsequent learning can occur. Where in "Important to know" we sharpen our choices by important knowledge (facts, concepts and principles) and skills (strategies and methods). "Worth being familiar with" is a broad brush knowledge assessed through traditional quiz or test questions would be sufficient, given for the course.

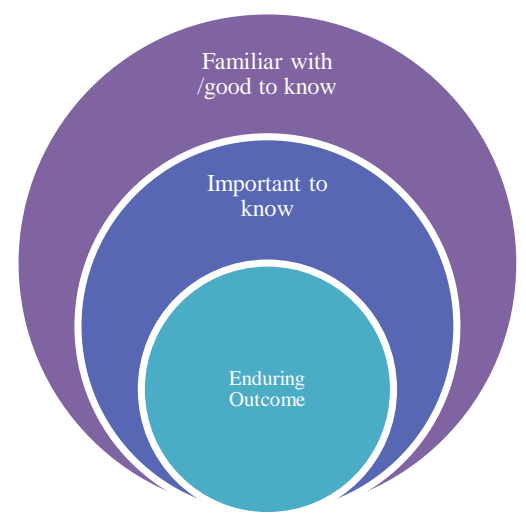

Fig. 3: Curricular Priorities

The Course learning outcomes (Enduring Outcomes) which should endure are listed below for Database Management System course.

CLO1 Explain the basic concept and the application of database system queries using SQL.

CLO2 Apply commercial relational database system by writing Queries using SQL and relational Database Theory to write relational algebra Expressions.

CLO3 Explain design principles for logical design of database including the ER model and normalization approach.

CLO4 Demonstrate the basics of query evaluation and apply query optimization techniques of transaction processing and concurrency control.

CLO5 Explain the basics of storage structures, 
indexing and page organization methods including

B-Tree and Hashing.

The three curricular priorities are addressed with specific assessment items as mentioned in the stage II of the backward design process.

\section{Worth Being familiar with:}

In these phase students must be able to know about subject so that instructor will make sure that students have the prior knowledge of relational algebra and basic knowledge of computer. Instructor will conduct the below mentioned assessment activity as an evidence of learning performance so that students can easily remember

- Quiz

- Think pair share

- Open book test, etc

\section{Important to know:}

Here students must be able to understand the importance of the topic and the instructor can make the students to attempt few of the formative assessments like

- Test after completion of every topic

- Seminar

- Online videos followed by online test

\section{Enduring Outcomes}

Where as in enduring outcome students have to remember it for the long time so that they never forget. Hence the pedagogical methods include:

- Collaborative Learning PracticesCollaborative learning practices can be implemented by grouping the students of slow and fast learners and make them work to solve a problem. At the end of the activity assessment in conducted as a part of collecting the acceptable evidence for assessing the learning activity for respective curricular priority.

- $\quad$ Project Based assignments

- Developing a small application so that students can know how the backend process is being done by DBMS. While developing an application students will design and create an application and while developing a project they can remember it for long term.

\section{Concept Mapping}

After identifying the curricular priorities for the course and including the assessment items for the topics the instructional activities (Pedagogical methods) are planned to make the learning happen more effectively. But in this paper the assessment items which are mostly formative assessments are mixed with the pedagogical activities like think pair share, quiz, Collaborative learning Practices, seminars, project based assignments, etc. Additionally concept maps have been introduced for the course to address the organizational and hierarchical approach of the course contents to understand the connections between the topics. The concept maps also presents the curricular priorities mapped with the topics. C-map tool has been used to draw the concept maps. C-map is a free source software available to download. The screen shot of the home page and working styles of the C-map software is shown in the Fig.4 and Fig. 5.

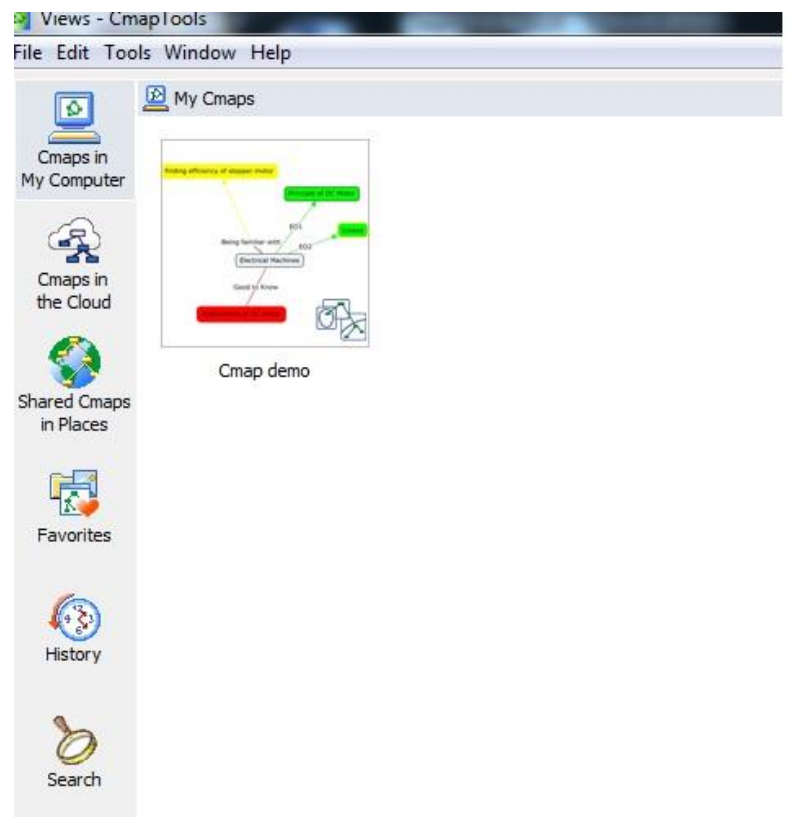

Fig. 4. Home page of C-map tool

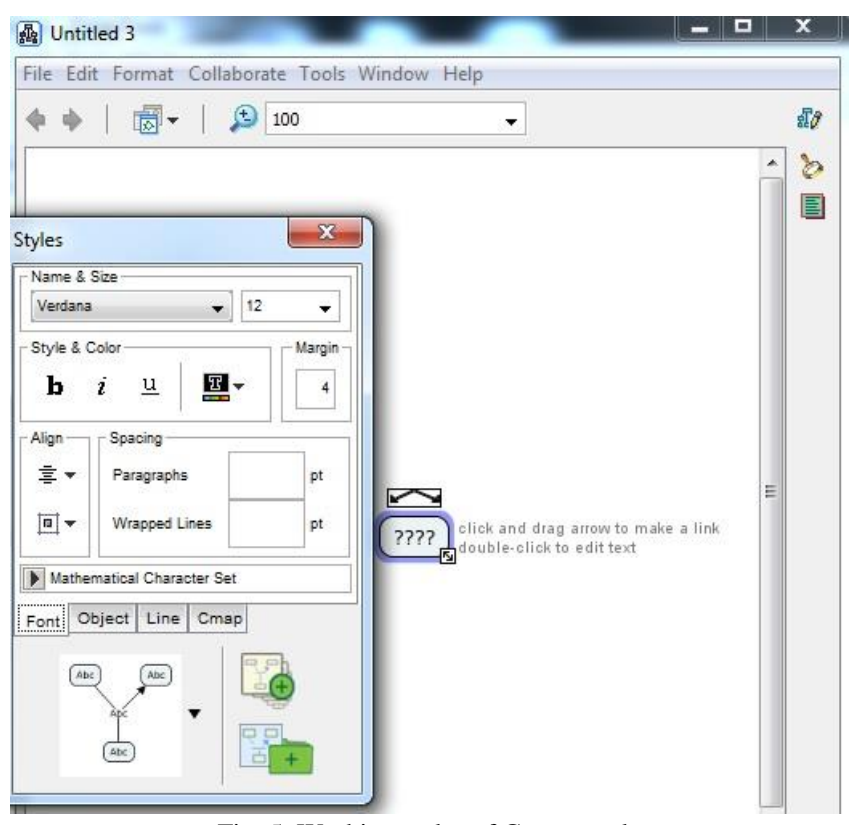

Fig. 5. Working styles of C-map tool

Concept mapping is an easy way to encourage very high 
levels of cognitive performance, when the process is done well. This is one reason concept mapping can also be a very powerful evaluation tool (Edmondson, 2000). CmapTools provides for the linking of any kind of digital resource (e.g. images, photos, videos, URLs, PDFs, other concept maps, etc.) to a concept or linking phrase to create in effect a knowledge portfolio or a knowledge model. The digital resource is now linked to the concept map and can be reached through the icon under the target concept.

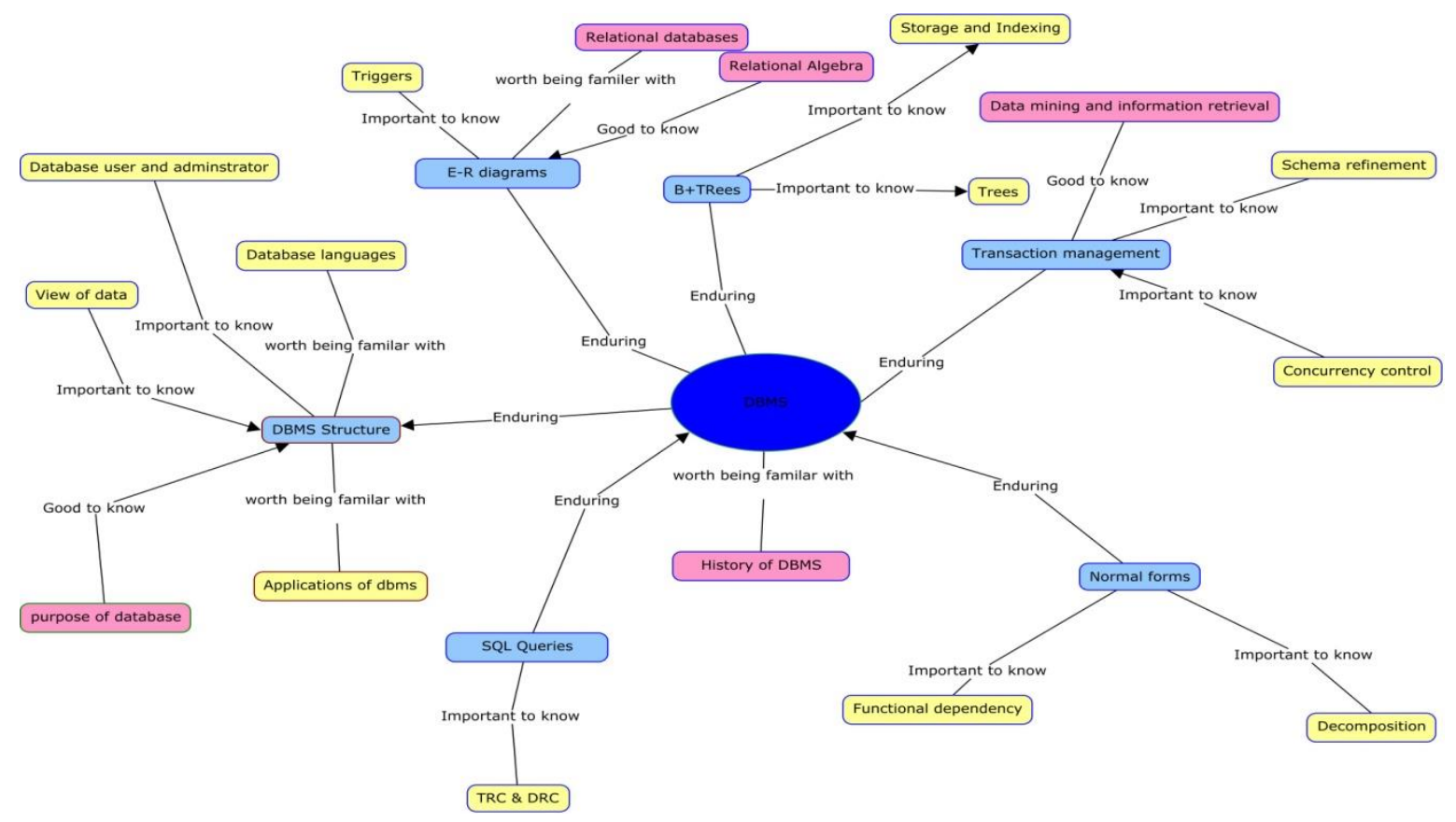

Fig. 6 Concept Map for the course Database management system

Finally, the map should be revised, concepts re-positioned in ways that lend to clarity and better over-all structure, and a "final" map prepared. When computer software is used, one can go back, change the size and font style, and add colors to "dress up" the concept map. Through the storing of concept maps in Cmap Servers, CmapTools encourages collaboration among users constructing the maps. When maps are stored in a server on the Internet, users with appropriate permissions (Canas et al., 2003) can edit shared concept maps at the same time (synchronously) or at their convenience (asynchronously). "Discussion threads" and Annotations" in the form of electronic "Post-It" notes can be used to make anecdotal comments on concept maps or during map construction. Using the C-map tool the concept is drawn for DBMS course content Color codes have been given to identify the three curricular priorities. Yellow color is used for "Important to Know" concepts, Pink for Good to know (Worth being familiar with) and Blue for the "Enduring Outcomes". By using this concept the students can know the content hierarchy and identify the curricular priories. It is a good tool used in a great way to build previous knowledge by connecting new information back to it. Using the c map tool the concept is drawn for DBMS course content shown in Fig. 6. Color codes have been given to identify the three curricular priorities. Yellow color is used for "Important to Know" concepts, Pink for Good to know (Worth being familiar with) and Blue for the "Enduring Outcomes". By using this concept the students can know the content hierarchy and identify the curricular priories. It is a good tool used in a great way to build previous knowledge by connecting new information back to it.

\section{Results and discussion}

The Database management system course has been taught in two methods. In the first semester the course taught to the students in a traditional method by using chalk and talk as the subject is open elective and was not core subject to them. The course was not reached to the students as expected and result was deprived. In this scenario to increase the performance of the students in the next semester the instructors have done background design process so that instructor can understand where the students are lagging. Later students have to know about course learning outcomes mainly on three aspects i.e.

- What is the course about?

- Why we have to learn the course?

- How the course is beneficial in future?

With the knowledge of these aspects the instructor created 
interest to the students using concept maps. Before starting the course by developing a concept map the instructor gave deep knowledge about the course by using content mapping using c-map tool with the support of the pedagogy and assessments. The improvement in the percentage of end examination results was observed compare to the previous semester. The bar graph representation shown in brown colour indicates the performance of the students when the content was explained mapped with concept maps. The results show that there is increase in the performance compared to the content taught without concept maps and backward design approach.

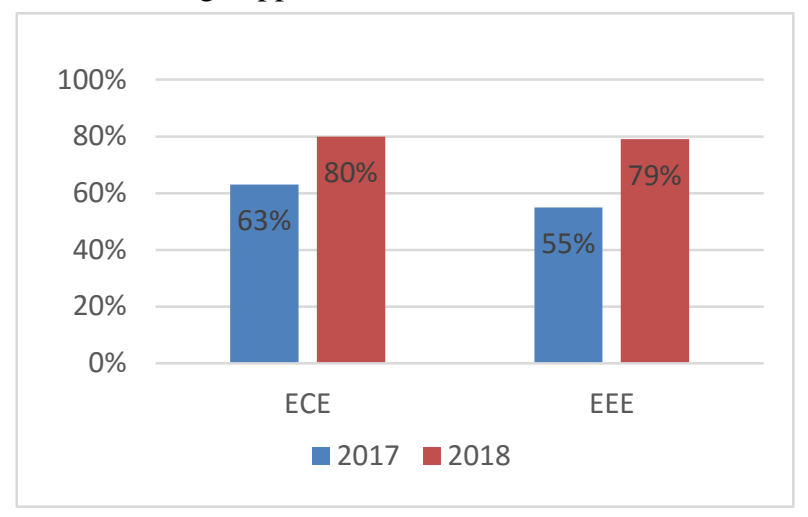

Fig.7. Comparison of results with and without concept map The assessment techniques that are planned and implemented during the course delivery impacted the student performance. It helps the instructors to judge the learning process by planning the assessments. The percentage attainment of the CLOs have also been improved which is not presented here. However the data is available in records. The result can be shown clearly in the bar graph Fig.7

\section{Conclusion and Future scope}

The concept map described here brings the structural understanding of the course database management System which is often difficult for the service disciplines without prerequisite knowledge. The curricular priorities have been identified and mapped with the content of the course. The pedagogical enabled assessments are planned with the curricular priorities mentioned. The development of the concept map has no boundary conditions. Better concept maps can be developed by the researchers in future which can have various designs and mapping techniques based on the pedagogical technique planned for the curriculum and course. New proposals on developing the concept maps by the students are being made to enable them to develop their own understanding on the subject. This retrieval of the information from their memory helps in retaining the information for long term. These concept maps enable the learners with self-discovery and structural knowledge of the concepts which helps them to solve complex problems in the real world through better conceptual knowledge for different applications.

\section{Acknowledgement}

I acknowledge the Director, KG Reddy College of Engineering \& Technology Dr. Rohit Kandakatla for his encouragement and creating a Scholarship of teaching and learning culture through professional development programs. I also thank Dr. R.S Jahagirdar, Principal for supporting the research in engineering education.

\section{References}

Andersonet, L.W (2000) A Taxonomy for Learning, Teaching, and Assessing: A Revision of Bloom's Taxonomy of Educational Objectives, Longman, New York.

Canas, A. J., Hill, G., Lott, J., \& Suri, N. (2003) Permissions and access control in CmapTools (Technical Report No. IHMC CmapTools 2003-03). Pensacola, FL: Institute for Human and Machine Cognition.

Edmondson, K. (2000) 'Assessing science understanding through concept maps'. In Mintzes, J., Wandersee, J. \& Novak J. (Eds.) Assessing science understanding (pp. 1940). San Diego: Academic Press.

Jonassen, D.H., \& Grabowski, B. L. (1993) Handbook of individual differences: Learning \& instruction. Hillsdale, NJ: Lawrence Earlbaum Associates.

Novak, J. D., \& Gowin, D. B. (1984) Learning how to learn: Cambridge University Press.

Strautmane, M. (2012) Concept Map-Based Knowledge Assessment Tasks and Their Scoring Criteria: an Overview. Paper presented at the Concept Maps: Theory, Methodology, Technology, The Fifth International Conference on Concept Mapping, Valletta, Malta

Brinley, K., Camellia W. S. (2019) Backward design as a mobile application development strategy. Education technology research \& development. 